\title{
Alcances de la categoría de dignidad en la reflexión moral de Arturo Andrés Roig
}

\section{Scopes of the category of dignity in the moral reflection of Arturo Andrés Roig}

Âmbito da categoria de dignidade na reflexão moral de Arturo Andrés Roig

\author{
Dra. Laura Aldana Contardi ${ }^{1}$
}

Recibido: 19/10/2016 - Aceptado: 2/11/2016

\begin{abstract}
Resumen
Este artículo busca profundizar aspectos de la propuesta filosófica de Arturo Andrés Roig con el objetivo de analizar un concepto fundamental de su reflexión moral: la dignidad. El punto de partida es la referencia al concepto kantiano de dignidad supuesto en la enunciación de la "moral de la emergencia". Luego, se retoman las tesis desarrolladas por Roig en las cuales se resignifican las categorías de "oikeiosis" y "conciliatio" para una ampliación de los alcances de la noción de dignidad.
\end{abstract}

Palabras clave: Dignidad - Arturo Roig - Moral de la emergencia - Filosofía latinoamericana - Sujeto.

\begin{abstract}
This article discusses aspects of the philosophical proposal of Arturo Andrés Roig with the aim of analyzing a fundamental concept in his moral reflection: dignity. The starting point is the reference to the Kantian concept of dignity supposed in the enunciation of the "morality of emergence". Then, the study takes the thesis developed by Roig which give a new meaning to categories of "oikeiosis" and "conciliatio" for widening the scope of the notion of dignity.
\end{abstract}

1 Argentina. Doctora en Filosofía, Universidad Nacional de Cuyo, Mendoza, Argentina. Becaria Posdoctoral en el Instituto de Ciencias Humanas Sociales y Ambientales - CONICET - Mendoza - Argentina. Profesora en la Facultad de Psicología- Universidad del Aconcagua. Contacto: acontardi@mendoza-conicet.gob.ar 
Keywords: Dignity- Arturo Roig- Moral of emergence- Latin American Philosophy- Subject.

\section{Resumo}

Este artigo procura aprofundar os aspectos da proposta filosófica de Arturo Andrés Roig, com o objetivo de analisar um conceito fundamental de sua reflexão moral: a dignidade. O ponto de partida é a referência ao conceito kantiano de dignidade suposto no enunciado da "moral da emergência". Logo, retomam-se as teses desenvolvidas por Roig nas quais resinificam-se as categorias de "oikeiosis" e "conciliatio" para um alargamento dos alcances da noção de dignidade.

Palavras-chave: Dignidade - Arturo Roig - Moral da Emergência- Filosofia latino-americana - Sujeito.

\section{Introducción: la moral de la emergencia}

En América Latina, desde los inicios de su cultura, se ha venido desarrollando una tradición moral que Arturo Roig rescata y reconstruye, tradición a la que él denomina "moral de la emergencia". La misma corresponde a una serie de expresiones teóricas y prácticas que se vinculan a la emergencia de movimientos sociales rastreables en la historia de América Latina. Algunos rasgos definitorios de esta moral son: la exigencia de un reconocimiento de la dignidad humana como bien universal y fundamento ético, la consideración de las necesidades como criterio ético normativo, el rescate de la subjetividad como motor de la conducta y la orientación hacia la solidaridad en el plano social. La moral de la emergencia es una expresión teórica de una experiencia propia de los pueblos latinoamericanos. La formulación, análisis y caracterización de esta moral se encuentra en Ética del poder y moralidad de la protesta (2002). En este texto confluyen, puede decirse, las diversas inflexiones de la cuestión del sujeto, cuestión central en la filosofía de Roig. La "moralidad de la emergencia" es, además, una moral del conflicto, del enfrentamiento entre lo subjetivo y lo objetivo (Roig 2002 7). El factum del que parte es el de la conflictividad social, en cuyo marco se manifiesta un problema central: el de la desvinculación entre el derecho y la justicia, entre las normas y aquello que los sujetos conciben como lo 
justo. Es allí, en consecuencia, donde se visualizan modos diversos de ejercicios sujetivos (Id. 41).

La experiencia de la moral emergente ha sido fruto de los movimientos sociales y la han expresado en sus escritos hombres de acción y de palabra; es una moral que ha sido y es vivida por los pueblos latinoamericanos. Como toda moral vivida, su desarrollo y sus principios son el fruto de una praxis. Roig nombra a José Martí y a José Mariátegui como exponentes de esta posición.

En relación con lo práctico moral, Arturo Roig distingue dos concepciones de acuerdo a la noción de sujeto que se juega en el ámbito del obrar. En la primera se considera lo práctico moral como un conocimiento fundado del fin al que debe dirigirse la conducta de los seres humanos, así como de los medios necesarios para alcanzar dicho fin, que junto con los medios apropiados pueden y deben ser deducidos de la "naturaleza humana". En la segunda se entiende a aquel saber como el conocimiento del impulso o de los impulsos de la conducta y de la ordenación o, si se quiere, codificación, de esa conducta conforme con ellos. No se trata de deducir de una naturaleza humana necesaria, un bien supremo y realidad perfecta a la que aspira nuestro ser, para lo cual ha sido creado, sino a partir de una experiencia moral de los motivos o impulsos sobre los que se intentará regular nuestra conducta. Cabe hablar, desde esta perspectiva, de una "condición humana". La moral formulada se orienta por la línea descrita en segundo término y a la que Roig califica como una "moral de los motivos" (cf. Roig 2002 20).

Roig manifiesta la necesidad de redefinir el quehacer filosófico y la filosofía misma desde el saber práctico-moral y de concederle a ese saber un lugar prioritario. En esto radica la función crítica de la filosofía, no una crítica de los límites de la razón, sino de las prácticas racionales -o irracionales- puestas en juego en el acto de preguntar filosófico. Esto implica un rescate de la potencialidad ética de la filosofía, del valor humano del filosofar. Esta tarea, advierte Arturo Roig, no resulta simple si se tiene en cuenta el largo proceso de descentramiento del sujeto que ha caracterizado a la modernidad y que en el ámbito filosófico decanta 
en la posición posmoderna que proclama la "muerte del sujeto" ${ }^{2}$. La doble tensión que se presenta entre la afirmación de los sujetos, como sujetos de discurso crítico, y la necesidad de volver la crítica sobre la sujetividad alcanzada, es lo que mueve a pensar. En otras palabras, se presenta la necesidad de esbozar herramientas teóricas que posibiliten explicitar esa tensión. El ejercicio de la sospecha y el temple crítico, como estado de ánimo y como actitud metodológica, se resume en la cuestión de qué y cómo hay que hacer para que la filosofía -no ya los filósofos- no sea inmoral. Ahora bien, lo que está en juego para Arturo Roig cuando se habla de moral es una concepción de ser y de la vida como fuerza emergente enfrentada a estructuras de "civilización" organizadas sobre valores opresivos, expresados en códigos. Se trata de una denuncia de la eticidad como deshumanización y contra cuyos valores la moral de la emergencia se entiende como un poner en movimiento una "moral de acción".

\section{Dignidad humana}

La dignidad es un concepto que se utiliza en la ética para referirse al respeto debido a la persona humana como tal. Es introducido decisivamente por Kant cuando en la segunda formulación del imperativo categórico afirma que el ser humano no debe ser usado nunca como un medio sino que debe ser siempre fin de los actos.

La idea de dignidad humana, afirma Dorando Michelini, ha sido objeto de numerosos debates filosóficos y ocupa un lugar relevante en el derecho internacional. Se trata, sin embargo, de un concepto controvertido, problemático podríamos decir. Mientras que algunos pensadores sostienen que se trata de un criterio ético fundamental, que ofrece también la base para la vincularidad jurídica, no solo en el ámbito de la política sino también, por ejemplo, en el de la biomedicina, otros se muestran escépticos respecto de los aportes y del alcance ético y jurídico que pueda tener el criterio de la dignidad humana (Michelini 2010 91). 
Los problemas claves a resolver en relación con el concepto en cuestión no son diferentes de los que presentan otros principios y normas éticos, a saber: es necesario indagar, por un lado, el problema de la fundamentación de su validez, y, por otro lado, las cuestiones vinculadas con las condiciones de aplicación situacional e histórica.

La categoría de "dignidad humana" cobra fuerza en los escritos éticos de Roig, aun cuando está presente desde el inicio de su obra. Precisamente esta categoría funciona como la idea reguladora de la moral emergente, y es entendida como una y la misma cosa con el ejercicio del a priori antropológico que implica una "posición de sujeto". La idea reguladora a la que se han aferrado los sectores emergentes es la de dignidad, por lo que es señalada como principio de ordenamiento de todos los valores. Una referencia ineludible en relación con la categoría de dignidad es la filosofía de Kant.

Kant distingue entre "valor" y "dignidad". Concibe la "dignidad" como un valor intrínseco de la persona moral. La dignidad no debe ser confundida con ninguna cosa, con ninguna mercancía, dado que no se trata de nada útil ni intercambiable o provechoso. "Aquello que tiene precio puede ser sustituido por algo equivalente; en cambio, lo que se halla por encima de todo precio y, por lo tanto, no admite nada equivalente, eso tiene una dignidad" (Kant 2012 93). Cuando a una persona se le pone precio se la trata como a una mercancía. En la Fundamentación para una metafísica de las costumbres, Kant afirma que "persona" es el sujeto cuyas acciones son imputables, en cambio una cosa es algo que no es susceptible de imputación. De esta manera, según Kant la ética llega solo hasta los límites de los deberes recíprocos de los hombres. En cuanto ser dotado de razón y voluntad libre, el ser humano es un fin en sí mismo, que, a su vez, puede proponerse fines. Es un ser capaz de hacerse preguntas morales, de discernir entre lo justo y lo injusto, de distinguir entre acciones morales e inmorales, y de obrar según principios morales, es decir, de obrar de forma responsable. Los seres moralmente imputables son fines en sí mismos, esto es, son seres autónomos y merecen un respeto incondicionado. El valor de la persona no remite al mercado ni a apreciaciones meramente subjetivas (de conveniencia, de utilidad, etcétera), sino que proviene de la dignidad que 
le es inherente a los seres racionales libres y autónomos. La autonomía moral es el concepto central con que Kant caracteriza al ser humano y constituye el fundamento de la dignidad humana: "La autonomía, es, de este modo, el fundamento de la dignidad de la naturaleza humana y de toda naturaleza racional" (Id. 94-95). Esta caracterización moral marca una diferencia entre los animales y los seres humanos, y, a la vez, deja abierto un espacio para el respeto a otros seres que pudieran ser moralmente imputables (cf. Michelini 2010). La dignidad es una instancia moral que distingue al ser humano de los animales, es una atribución propia de todo ser humano en tanto que miembro de la comunidad de seres morales; esto es lo que lo distingue de los animales. Para Kant negar o lesionar la dignidad de otro es afectar a la humanidad en mi persona, mi propia dignidad moral como ser humano.

Las consecuencias prácticas que se desprenden de este modo de comprender la dignidad derivan en la formulación kantiana del imperativo categórico. El reconocimiento de la dignidad de todo otro conlleva que cada uno debe ser tratado siempre al mismo tiempo como fin y nunca solo como medio. La comprensión moral y el contenido esencial del imperativo categórico es presentada por Kant como la segunda fórmula: "Obra de tal modo que uses a la humanidad, tanto en tu persona, como en la persona de cualquier otro, siempre y al mismo tiempo como fin, y nunca como un medio". Se trata, según Kant, de otra formulación del imperativo que está implicada y se deduce analíticamente del principio. Esta segunda fórmula abre a la comprensión del alcance de la primera. En este enunciado la noción de "la humanidad como fin en sí" no es representada como un fin subjetivo que cada cual se propone realizar, sino como el fin objetivo que, más allá de los fines que cada cual tenga, constituye como ley la condición suprema limitativa de todos los fines subjetivos. Lo que diferencia y define al hombre es su capacidad de obrar conforme a reglas que él formula mediante su razón. Estas reglas de la razón muestran el camino a seguir, e indican los medios adecuados que hay que usar para alcanzar los diferentes fines que los hombres se proponen ${ }^{3}$. 
Cuando se objetiva al otro y se lo instrumentaliza, cuando se lo utiliza para los propios fines, se lesiona su dignidad.

Volviendo al contexto de la moral de la emergencia, veamos cómo es definida la dignidad por Roig ${ }^{4}$. La afirmación de nuestra dignidad es una misma cosa con el a-priori antropológico, el cual es la necesidad de autoafirmación, impulso de "perseverar en el ser"; es una posición sujetiva que implica la autoconciencia y el autorreconocimiento de sí como valioso ${ }^{5}$. La definición de dignidad está dada en estos términos:
(...) es la necesidad primera, la forma por excelencia de toda necesidad humana que da sentido e introduce un criterio para la evaluación del universo de necesidades y de los abigarrados modos que la humanidad ha generado para satisfacerlas. Se trata de una 'dignidad humana' plena y que es, por eso mismo, también nacional y continental. Es la dignidad como la entiende un hombre que se siente integrante de esta 'nuestra América'. 'Dignidad' es entre nosotros palabra cargada de esperanza, con profundas raíces en nuestra cultura (Roig 2002 115).

Para explicar cómo se ha de interpretar la noción "dignidad humana", Roig se vale de cuatro principios, los cuales son cuatro pilares fun-

\footnotetext{
4 Un trabajo de interés que plantea la cuestión de la dignidad humana es el artículo "El hombre en cuanto objeto axiológico" de Arturo Ardao (Ardao 1993 135-147). Una distinción que acentúa el autor es que la dignidad puede ser entendida como dignidad de la condición humana cuando el hombre es siempre entendido como fin en sí. Esta es inalienable e imprescriptible. $Y$ en otro sentido puede ser entendida como la dignidad moral, que es aquella que se conquista o no se conquista, se conserva o se pierde. La primera, dignidad de la condición humana, es anterior e independiente de la dignidad moral; no se conquista, no se pierde, no se altera. Esta es la que se enuncia en la formulación del imperativo categórico kantiano que entiende al hombre como fin en sí. De la dignidad intrínseca de la condición humana extrae su razón de ser un conjunto de principios cuyo titular no es ni la humanidad en su abstracción genérica ni un determinado tipo de hombre, sino cada hombre en su personal concreción. Estos principios son los derechos humanos, la igualdad de derechos y la igualdad entre los seres humanos. En ese primario orden de valoración del hombre por el hombre radica la Declaración Universal de los Derechos Humanos. 5 cf. Fernández Nadal 2001165 y Roig 2009.
} 
damentales de su filosofía. Ellos son: 1. El principio de perseverancia en el ser o principio conativo, también llamado a priori ontológico, de Spinoza. 2. El principio de auto y heteroconocimiento o a priori antropológico, de Hegel. 3. El principio de la naturaleza intrínseca del valor del ser humano o a priori ético axiológico, de Kant y Marx. 4. El principio del duro trabajo de la subjetividad o de la emergencia de los oprimidos que constituye el a priori ético-político, cuyos símbolos son Calibán y Antígona ${ }^{6}$. Este último principio tiene en el pensamiento de José Martí un desarrollo particular en el cual Roig fundamenta también la noción de dignidad humana. De la interpretación que se dé a la dignidad humana a partir de estos principios surgirá el criterio para la evaluación de las necesidades.

Hemos de referirnos brevemente a estos principios para aclarar en qué consiste cada uno. El principio de perseverancia en el ser se basa en que "toda cosa en cuanto es en sí se esfuerza por perseverar en su ser" (Roig 2002 132). El principio que Roig llama a priori antropológico, eje central de todo su pensamiento, es la constitución de la autoconciencia -condición de constitución de todo sujeto- e implica la transformación del universal principio conativo porque queda expresado en el hecho de que "nuestro 'perseverar en el ser' quiere serlo humanamente, es decir, en cuanto seres valiosos o dignos" (Ibíd.). Este principio de autoconocimiento queda expresado en dos imperativos hegelianos: "tenerse a sí mismo como absolutamente valioso" y "tener como valioso el conocerse a sí mismo"7. La profundización del principio conativo y su formulación como a priori antropológico suponen la autoconciencia y el reconocimiento de la dignidad de todo otro. $Y$ no hay otro modo de señalar esa dignidad sino a partir de lo que desde Kant se ha caracterizado como un reino de los fines y, desde Marx, como modos intrínsecos de ejercer el valor, más allá de los valores de uso y de los valores de cambio. Ser digno, ser valioso, para el ser humano es serlo intrínsecamente, advierte Roig, y el verdadero autoconocimiento se cumple cuando todos asumimos que 
no somos medios sino fines. Pero este nivel de profundización sólo es posible "por el "duro trabajo" de la subjetividad contra la objetividad, de la moral de los oprimidos contra la ética de los opresores (Id. 133).

La formulación ética de Arturo Roig se muestra como un modo de responder a la crisis moral de finales del siglo veinte, crisis que se ve reflejada en el panorama de la filosofía práctica donde numerosas concepciones morales conviven en medio del conflicto entre moralidad y eticidad.

Arturo Roig interpreta que el impulso al que se refiere Spinoza ${ }^{8}$ no se lleva adelante del mismo modo ni en forma plena por todos los seres humanos. Hay modos inauténticos de afirmación. Precisamente, la pauta señalada en Kant, anterior al "sujeto trascendental" y que deriva, según la interpretación de Roig, del sujeto real histórico kantiano, la pauta del a priori antropológico, es retomada luego por Hegel y enunciada como un "tenernos a nosotros mismos como valiosos". Frente a los principios de Kant y Hegel el conatus plasma el problema del fundamento de la moralidad, sin renunciar a lo universal a pesar de su materialidad y sin caer en una hipóstasis del sujeto (cf. Roig

8 En Teoría y crítica del pensamiento latinoamericano (2009 [1981]) es posible rastrear la relación entre conatus y a priori antropológico. Roig se refiere a la Ética de Spinoza (2000), porque allí aparece enunciada la noción de esfuerzo o conato. En la cuarta parte de la Ética de Spinoza podemos leer: "El deseo es la misma esencia del hombre, esto es, el conato con el que el hombre se esfuerza en perseverar en su ser" (Spinoza 2000196 [178]). Ahora bien, el conato no se refiere a una voluntad perseverante inherente al impulso ciego. Es interesante resaltar un punto en el que Arturo Roig no se detiene en el texto al que nos referimos pero que ilumina lo que el conatus mienta. En la tercera parte de su Ética, Spinoza se refiere del siguiente modo al conatus: "Este conato, cuando se refiere sólo al alma, se llama voluntad; en cambio, cuando se refiere a la vez al alma y al cuerpo, se llama apetito. Éste no es, pues, otra cosa que la misma esencia del hombre, de cuya naturaleza se sigue necesariamente aquello que contribuye a su conservación y que el hombre está, por tanto, determinado a realizar. Por lo demás, entre apetito y deseo no hay diferencia alguna, excepto que el deseo suele atribuirse a los hombres en cuanto que son conscientes de su apetito; $y$ por tanto puede definirse así: el deseo es el apetito con la conciencia del mismo. Por todo esto consta, pues, que nosotros no nos esforzamos, queremos, apetecemos ni deseamos algo porque juzgamos que es bueno, sino que, por el contrario, juzgamos que algo es bueno, porque nos esforzamos por ello, lo queremos, apetecemos y deseamos" (Spinoza, 2000133 [103]). 
2002 24). El conatus spinociano tiene, además, un antecedente en la categoría "oikeiosis" de los estoicos. La noción de Spinoza implica una apertura a la corporalidad y por lo tanto no se reduce al ser humano, sino que puede ser pensada en relación con todo ser vivo ${ }^{9}$.

Según la interpretación de Roig, el a priori antropológico expresa en Kant la existencia "disimulada" de un sujeto no trascendental sino empírico, es decir, histórico. En Hegel, dejando de lado lo ontológico, expresa un sujeto que para conocer el mundo se pone en acto de afirmación de sí mismo, comenzando por el reconocimiento del valor de la subjetividad y de su autoconocimiento como hechos históricos (Roig 2002 24). La moral emergente tiene como trasfondo el perseverar en el ser spinociano, quien ve en la naturaleza entera, incluyendo lo humano, un nexo unitario, aun cuando Roig entiende que en el caso de Spinoza se trata de una comprensión ajena a lo histórico ${ }^{10}$.

9 Un estudio valioso en relación con la lectura roigiana de Spinoza es el de Gerardo Oviedo. Rescatamos de allí una de sus tesis en relación con la formulación de la moralidad de la emergencia que tiene en su base una serie de apropiaciones teóricas que realiza Roig. Gerardo Oviedo se ha referido a la cuestión del siguiente modo: "Fruto de ese entrecruzamiento con fuentes del discurso filosófico de la modernidad que le preceden -de Spinoza a Kant y Hegel-, el nunca cristalizado ni taxativo "marxismo" de Roig, se des-dogmatiza, re-significa y estiliza más bien en una progresión categorial que conduce del conatus y los a priori hasta la idea de "emergencia". Pues en ese tránsito reflexivo Roig jamás abandona su denuncia de la opresión capitalista e imperial en sus múltiples modalidades, desde la represión estatal periférica hasta la globalización neoliberal. Semejante diálogo con Marx atravesado por Spinoza -si se acepta esta descripción de conexiones a título de hipótesis de lectura- asume en los escritos roigianos una impulsión renovadora que rebasa el canon y el paradigma de una filosofía áulica euro-occidental "pura", tal como se venía asimilando desde las reglas de la profesión de una cultura académica argentina al fin "normalizada" (Oviedo 2010).

10 Un fragmento del texto de Spinoza donde estimamos se muestra su concepción "a-historicista" en la que lo contingente queda opacado es, por ejemplo, la siguiente: "Porque la naturaleza es siempre la misma, y una y la misma en todas partes es su virtud y potencia de actuar; es decir, que las leyes y reglas de la naturaleza, según las cuales se hacen todas las cosas y se cambian de unas formas en otras, son en todo tiempo y lugar las mismas; y por tanto, una y la misma debe ser también la razón de entender la naturaleza de las cosas, cualesquiera que sean, a saber, por medio de las leyes y reglas universales de la naturaleza" (Spinoza 2000126 [95]). Se trata de una concepción de la naturaleza, y consecuentemente, de la "naturaleza humana" a la que Arturo Roig le encuentra limitaciones. 
La dignidad humana es una con el ejercicio del a priori antropológico y éste se ejerce cuando el sujeto se sabe sujeto de derechos, cuando se autoafirma y autovalora. Cada forma de ejercicio de este a priori significa una forma de emergencia en la que se juega la subjetividad. Se trata de una lucha en la que se manifiesta la afirmación del sujeto en su condición humana (cf. Roig 2001). El a priori implica un acto de voluntad que supone que nos entendemos y declaramos sujetos de derecho en cuanto no hay modo de valer que no implique ejercer derechos. El valor primero, ordenador de todos los derechos, es el de la dignidad.

El criterio ordenador de las necesidades, junto con no atender solo a las preferencias individuales de cada quien, aunque estas no deban ser desestimadas, permite no caer en la inversión que propone la lógica del neocapitalismo, que pretende ignorar las necesidades. Se ha de subordinar, entonces, la propiedad a la dignidad como principio ordenador y primario de la objetivación social y cultural, como principio regulador de la reproducción material y espiritual de los seres humanos. Dignidad no solo es la única vía para no reducir al ser humano a la categoría de mercancía, sino que es la única vía para fundar la resistencia, la que fuera enunciada como derecho fundamental por la Convención Francesa. Ese derecho de resistencia es al mismo tiempo derecho de disidencia, que se ha de ejercer dentro de los cauces de la ley cuando la ley posibilita salvar injusticias dentro del derecho, pero también derecho que se ha de ejercer fuera de la ley, si es necesario, cuando la ley es injusta.

Los derechos humanos tienen un alcance mundial, pretenden estar más allá de toda discriminación, de toda marginación, de toda exclusión, de toda diferenciación o preferencia. Son, como la dignidad, aquello de que goza cada ser humano por el hecho de su condición de humano.

La Declaración Universal de los Derechos Humanos fue proclamada por la ONU durante la segunda posguerra mundial, el 10 de diciembre de 1948. La Declaración logró mantener la hegemonía del enfoque liberal, que partía de la concepción de las libertades individuales como único derecho humano posible. Las presiones de los países 
latinoamericanos y del bloque soviético lograron que aparecieran registrados temas como la discriminación racial, social y económica; el derecho al trabajo, la educación, la salud, la alimentación, el vestido, la vivienda, la seguridad social y la propia identidad cultural. Desde entonces, los distintos derechos se fueron incorporando a las Constituciones nacionales a partir de tratados internacionales. Por orden cronológico de aparición de demandas colectivas, se reconocen tres "generaciones" de derechos: los cívicos y políticos; los económicos, sociales y culturales, y los que se centran en la preservación del ambiente. Este amplio reconocimiento ahondó la controversia sobre la conflictividad en que se encuentran los derechos individuales y sociales. El derecho individual de la propiedad requiere la no intervención del Estado, mientras que el derecho social al trabajo o a la alimentación implican, para su efectivización, una fuerte regulación estatal que pueda afectar el derecho de propiedad. Algunos autores sostienen que hay que considerar ciertos derechos como fundamentales y sugieren que se establezca una jerarquización y que en caso de conflicto prevalezca aquel que ocupa el primer puesto. En este sentido Arturo Roig propone, revalorizando una larga trayectoria en el pensamiento latinoamericano que tiene exponentes destacados en Simón Bolívar o José Artigas, que el respeto por los derechos humanos se hace efectivo bajo el principio ordenador de la dignidad humana, atribuyéndole a esta un papel regulador ${ }^{11}$.

Cuando el derecho positivo, las leyes, va en contra de los derechos, lo que queda es la resistencia, el disenso y la revolución por parte de quienes han sido sometidos a cualquier forma de menosprecio en su dignidad. El derecho injusto tiene que ver con la fuerza, con el poder "desde arriba", principalmente desde el Estado.

El principio de la dignidad no encabezó la célebre Declaración de los derechos del hombre y del ciudadano de la Convención Francesa de 1789. Allí decía que los hombres nacen y permanecen libres e iguales en derechos. En cambio, en la Declaración universal de los derechos 
del hombre de las Naciones Unidas del año 1948 se afirma: Todos los seres humanos nacen libres e iguales en dignidad y derechos. De modo tal que no es la propiedad el principio sagrado e inviolable sino la dignidad (cf. Roig 2002 169-170).

Dignidad y propiedad privada son principios ordenadores que juegan, aun cuando no necesariamente, como antagónicos. Ambos ordenan los derechos humanos, estableciendo prioridades a las contradicciones que el ejercicio de esos derechos da lugar, ordenan también los sistemas de producción y de distribución de bienes. Aquellos derechos y los sistemas de producción se condicionan mutuamente, y de ese condicionamiento surgen los límites y las posibilidades de las formaciones sociales. Propiedad y dignidad no son simples derechos, son principios ordenadores universales. El ponerse el sujeto como valioso supone un acto de voluntad, esto indica una conciencia de historicidad, es decir, cada forma de ejercicio del a priori antropológico depende en su origen y desarrollo de una a posterioridad.

¿Estas afirmaciones de Roig hacen posible decir que rechaza la categoría de "propiedad"? De ningún modo. Lo que es rechazado por Roig es que la propiedad instituya un principio ordenador de los derechos humanos, de la producción y distribución de bienes, y, por lo tanto, de la democracia. La categoría de propiedad tiene un lugar de peso en la moral de la emergencia en cuanto se vincula a la de "tener", tan importante como la de ser. Sin embargo, una vez más juega un papel decisivo la noción de crítica en cuanto no es lo mismo la categoría del tener en relación a las necesidades que a las preferencias. La dignidad humana como criterio ordenador da sentido y pone límites a la propiedad, así como respecto a la tenencia, cuyo valor sin este referente puede degradarse hasta los límites de lo inhumano (cf. Roig 2002 174-178).

Los actos de emergencia son un derecho, como el derecho a "decir no" del que nos habla Julio De Zan, quien afirma que la historia y la teoría política nos hacen pensar que siempre habrá de nuevo situaciones excepcionales en que la sociedad (o el pueblo) diga: ¡basta!, interrumpiendo la continuidad del orden injusto establecido. No es posible privar a los hombres y a los pueblos del ejercicio de su liber- 
tad fundamental de decir que no, de cambiar, de proyectar nuevos comienzos en la historia de la sociedad y de pensar otras instituciones que hagan posible más democracia, más justicia y más libertad, en otros términos, dignidad (cf. De Zan 2002).

\section{Oikéiosis: hacia una ampliación de la dignidad}

Nos vamos a referir a dos conceptos que posibilitan bosquejar una trama complementaria para el tratamiento de la fundamentación de la ética y más particularmente en relación con la categoría de dignidad humana. Estos conceptos son los de oikéiosis y de conciliatio. Para comprender cuáles son sus alcances vamos a recurrir a tres artículos en los cuales Roig recupera el hilo de una trama que la tradición filosófica no ha acentuado, tal vez, lo suficiente. El tema desde el cual se abordan los conceptos mencionados es el de la naturaleza a partir de una reconstrucción del pensamiento clásico griego y romano haciendo foco en las propuestas de los sofistas, los cínicos, los epicúreos y los estoicos. Los artículos de Roig que analizamos son: "La primera propuesta de una filosofía para la liberación en Occidente: el regreso a la naturaleza en los sofistas, los cínicos y los epicúreos", "La conducta humana y la naturaleza" y "Naturaleza, corporeidad y liberación". Todos ellos han sido incluidos en Ética del poder y moralidad de la protesta (2002).

Fue con los sofistas con quienes comenzó a delinearse la distinción entre el mundo de la naturaleza y lo que puede llamarse el mundo de la cultura. En las posiciones de los filósofos naturalistas anteriores, es decir entre los presocráticos, esos mundos se hallaban "fundidos y confundidos". Claro está que aún dentro de los sofistas podrían señalarse posiciones divergentes, sin embargo, Roig destaca una en la que se produce algo que puede caracterizarse como un "regreso a la naturaleza" y que puede ser leída como una posición de liberación o de corte liberacionista.

Lo que se caracteriza como el "regreso a la naturaleza" en una línea de la sofística parece entrar en contradicción con la versión según la cual los sofistas juegan un papel importante en el paso de la visión cosmológica, propia de la filosofía jonia, hacia una comprensión an- 
tropológica del mundo y de la vida. Roig se pregunta, entonces, qué relaciones o diferencias muestra el concepto de physis en los milesios, por ejemplo, y el mismo concepto en los sofistas como Antifonte e Hipias de Elis. Se trata de concepciones diferentes de la "naturaleza", la que es rechazada o de la que se predica su positividad en relación con su opuesto: el mundo de lo convencional o de las "leyes humanas". La "naturaleza" en este contexto no es el "cosmos", sino la que se opone a la ciudad, y más específicamente, a las regulaciones de la vida que impone la cultura de las ciudades-estado. Este sentido de "naturaleza" se aproxima a las nociones de "campo" y "paisaje", tal como se lee en el Fedro, en el que Sócrates declara que no necesita ni desea salirse de las murallas de la ciudad para filosofar y se declara como filósofo-ciudadano. Es así que no solo rechaza la cosmología anaxagórea sino también este nuevo sentido de la physis que se gesta en la contraposición entre naturaleza y nomos. Según Roig este nuevo concepto implica un tipo distinto de racionalidad que en el plano de la vida humana supone, a su vez, la contraposición entre moral subjetiva y objetiva. En virtud de esto la noción de physis se entendía como un determinado lugar de vitalidad primaria al que se ha de regresar, en contra de la "ley de la ciudad". Con lo que la oposición entre una moral "según la naturaleza" o según las "leyes" no queda explicada suficientemente ateniéndose a la oposición entre "naturaleza" y "cultura", ya que la naturaleza, no ajena a las mediaciones, es una forma cultural.

La racionalidad a la que se hace referencia abarca en distintos niveles tanto a la naturaleza como a la cultura y no se identifica con el "logos" de los cosmólogos. Por ejemplo, en Heráclito, el logos es una categoría cosmogónica y cosmológica, a pesar del contenido antropológico de su posición. En la sofística, en cambio, está la distinción entre la racionalidad "según la naturaleza" y otra racionalidad según el mundo de las "convenciones". Esta oposición posibilita lecturas disímiles de los grandes mitos relativos a la vida de los héroes, en particular los relatos de Prometeo y Heracles, que para Roig constituyen relatos que impactan en cómo se concibe el sentido de la vida humana, el trabajo, las desigualdades humanas y la liberación (cf. Roig 2002 55-58). 
En relación con el trabajo es posible ver una dicotomía entre una comprensión positiva, unida a una idea de "progreso", muy clara en el mito de Prometeo tal como lo entendieron Esquilo y Protágoras, la que anticipa según Roig la problemática de "barbarie" y "civilización"; y otra, negativa, que ve en el trabajo una maldición y la negación de un desarrollo espontáneo de la vida. No es lo mismo el trabajo que ordena y crea, junto con el mundo de las técnicas, Prometeo, que el trabajo de liberación de Heracles, quien "desata" a Prometeo que pasará de este modo de su estado de "encadenado" al de "desatado". "La libertad respecto del trabajo no es, pues, la clásica eleuthería, sino que es otra cosa, es liberación, apólysis" (Roig 2002 59). Lo que destaca Roig es que para Protágoras la ciudad y el trabajo constituyen un lugar y tarea humanizantes por excelencia.

El sentido profundo del lema protagóreo del "hombre como medida de todas las cosas" tiene como supuesto un tipo de relación entre el individuo y el Estado en el que se intenta reordenar las fuentes de toda eticidad sin negar los niveles de moralidad primarios y en el que no se desconoce, además, la relación dinámica entre ambos niveles.

Lo que está en juego en todo el planteo precedente es la contraposición de dos modos de entender la libertad: como eleuthería habrá de concluir en la libertad interior del estoico, que es de algún modo continuador del socratismo, y como apólysis en otros. La libertad entendida como apólysis, afirma Roig, avanza "hacia el desmontaje permanente de las estructuras opresivas, anteponiendo el ser humano a las leyes" $(2002,61)$. Es decir, que este modo de comprender la libertad sería un "anticipo" de lo que el filósofo mendocino llama "liberación" y también actos de emergencia.

El sofista Antifonte niega el principio de la desigualdad, rechaza la distinción entre helenos y bárbaros y también la distinción entre amos y esclavos. "En esto nos comportamos como bárbaros, puesto que por naturaleza todos, bárbaros y griegos, somos iguales en todo. Basta observar las necesidades naturales de todos los hombres" (Roig 2002 63). De este modo, la confrontación entre dos niveles de racionalidad se hace patente: uno es la naturaleza, otro las convenciones, esto es, las leyes establecidas por los hombres frente a lo que puede 
llamarse vida. De acuerdo a este análisis el "regreso a la naturaleza" no implicaba "salirse de la ciudad" sino una denuncia de las formas cuya función es la de establecer "ataduras", la función contraria al desatamiento o desligamiento.

Atendiendo a esa "naturaleza" conforme con la cual todos somos iguales, Hipias lleva a cabo la reordenación de los saberes (máthema) y de las técnicas (téjnai) a los que accede tratando de alcanzar formas no mediadas. Opinaba que la posesión global de los conocimientos le permitía eliminar las mediaciones de los libros y de los otros filósofos, así como la posesión global de las artesanías, incluidas las del lenguaje, tendía a la eliminación de todas las formas de mediación que alejan al hombre de la naturaleza. Este tipo de vida, estima Roig, era posible en alguien que se sentía desatado, liberado, respecto de la ciudad y, en particular, de su mundo productivo, tanto en relación con sus conocimientos como en relación con las técnicas (cf. Roig 2002 64-65).

Los planteos descriptos se encuentran en términos similares en los cínicos. Antístenes y Diógenes son los exponentes que Roig resignifica en esta línea genealógica de la liberación. Cuando Diógenes de Sínope, sucesor de Antístenes, opone abiertamente la ley y la naturaleza, queda en evidencia que la noción de "virtud" tal y como se entiende en el marco de la posición aristotélica, había sufrido un desplazamiento. La vida urbana, habría afirmado Diógenes, fue el comienzo de toda injusticia. Se trata de una contradicción dada en el seno mismo de la ciudad desde la cual se proponía hacerse cargo de la necesidad de reintegrarse a la physis en contra del mundo artificial nómico. Los cínicos acentúan su posición en el mundo de los símbolos que ponen en juego entre los que se destacaron la vestimenta, sus atuendos, las habitaciones en las que descansaban. Es claro que el mundo simbólico al que apelan se sostiene en el "regreso a la naturaleza", entendida como un mundo de simplicidad, ingenuidad, inmediatez. Sin salirse de las ciudades vivían marginalmente en ellas, rechazaban la vestimenta "decente" y elegían una capa grande que les permitía vivir a la intemperie; rechazaban también la privacidad y el retiro de la vida hogareña y los alimentos servidos en la mesa. Esta conducta, afirma Roig, refleja la crisis de la sociedad doméstica tradicional y la 
voluntad de reordenar ese nivel de vida, desvirtuado de algún modo por las costumbres cuyo orden no era extraño al mundo legal de la polis (cf. Roig 2002 65-68).

La exigencia del "regreso a la naturaleza" se manifestó como un esfuerzo por eliminar las mediaciones a través de una reducción constante de las necesidades y de una supresión de todo lo que consideraban superfluo, llevando al límite las necesidades mínimas hasta llegar a los extremos concebibles. No surge expresamente de sus textos conocidos que su modelo haya sido la simplicidad de la vida campesina sino la vida de los animales, su simplicidad y su ingenuidad e inocencia. En este marco la areté, conforme con la cual se ha de vivir, es aquella fuerza que permite descubrir algo que ha sido ocultado por los convencionalismos y que sin embargo la han dado los dioses: la vida simple.

Es así que la moralidad de los cínicos es espontánea e inmediatamente apegada a la vida misma, enfrentada a la legalidad sobre la que se ha construido la ciudad-Estado. La physis a la que se pretende regresar, en contra del nómos, es un referente imaginario, afirma Roig, al que se le concede una especie de "poder de revelación y al que se cree poder llegar mediante una sucesiva y dura tarea de quiebra de mediaciones" (Roig 2002 70).

El concepto de "libertad" como desatamiento, rescatado por Roig, se apoya en la polémica que ponen de manifiesto los cínicos contra el realismo y a favor del nominalismo. Esta posición nominalista es coherente con la defensa del nivel de moralidad que Roig acentúa, nivel primario cuyas contradicciones con las normas de la ciudad eran profundas. En polémica con Platón se rechaza, además, el saber de las esencias y se interesan en lo que Roig denomina una "filosofía de la corporeidad", que niega lo universal y afirma lo individual.

Ante el imperio de los universales a los que se les confiere valor ontológico y desde ellos se trata luego de justificar las normas que han de regir la vida humana, no cabe posición más sana que la de estos nominalistas y nos revela de modo muy claro cuál era su posición desde el punto de vista social (Roig 2002 72). 
Los cínicos se inclinaron hacia la parte sufriente de la sociedad de su época, predicaron la igualdad ante la naturaleza que asumió el modo de una crítica a las bases sobre las que se sostenía la sociedad esclavista. Destaca Roig que fueron los primeros en admitir una mujer filósofa como miembro activo dentro de la secta.

En relación con los dos niveles de la moral, el dado inmediatamente con las necesidades humanas y sus funciones vitales y el otro, organizado desde la ciudad, el papel de la mujer resulta paradigmático. La contraposición entre naturaleza y razón o espíritu y entre cuerpo y alma serían otros modos de expresar la oposición physis y nomos, sobre estas últimas se han establecido relaciones jerárquicas entre mujer y varón. Se trata de dos niveles de racionalidad en los que las funciones para ambos géneros son impuestas, "dadas". La utopía de "salvar las mediaciones" impulsó a algunos sofistas, luego a los cínicos y también es visible en los epicúreos, sin embargo en el marco de la propuesta de Roig se entiende que ese regreso a la naturaleza, o el intento de eliminar las mediaciones, funciona como una idea reguladora, como un horizonte de sentido para las acciones pero que a partir de asumir las tesis de las filosofías de la denuncia y de la teoría de las ideologías ha de considerarse a la "naturaleza" como un referente inalcanzable, teniendo en cuenta que es imposible eliminar todas las mediaciones.

Uno de los asuntos que lleva a Arturo Roig a recuperar las posiciones de las escuelas filosóficas de la antigüedad es la necesidad de fundamentar las acciones morales. Como hemos visto la moral de la emergencia tiene como idea reguladora la dignidad humana. Ahora bien, Roig expresa que:

A la lucha por la dignidad como pueblos se ha sumado el más profundo y grave de la sobrevivencia como humanidad. La responsabilidad de los hechos que han suscitado la "alarma ecológica" es, por cierto, mayor para unos que para otros, en un mundo partido por la desigualdad de la riqueza y del poder... (2002 78).

Cuando habla de la alarma ecológica puede pensarse en los crecientes niveles de deforestación, explotación, contaminación y depredación. 
Si retomamos la caracterización realizada podemos decir que la moral emergente, como expresión teórica de la experiencia propia de los pueblos latinoamericanos, es un ejercicio del a priori antropológico. De la reflexión sobre este ejercicio Roig desprende la norma cuyo valor imperativo depende del grado de conciencia moral con el cual se la asuma. Esa norma se condensa en la máxima de considerarnos como fines y no simplemente como medios, en este sentido es que la categoría de la dignidad humana cobra peso decisivo. El ejercicio del a priori antropológico es una actualización del "principio conativo" que lleva a todo ente a perseverar en su ser. Esta propuesta teórica se enriquece con el rescate de las posiciones estoicas $y$, como veremos, con la propuesta de Ignacio Ellacuría. Roig intenta de este modo no limitar el ejercicio de las normas morales a una posición antropocéntri$\mathrm{ca}$, pues el erigir al hombre como centro no ha resultado un ejercicio legítimo en todos los casos. En efecto, por ejemplo, desde una posición teológica que puso al mundo al servicio del hombre por ser vicario de Dios, como desde el discurso científico que propició al hombre como amo y señor de la naturaleza, lo que se posibilitó fue una relación de dominación. En esta relación entre amo y esclavo, hombre-naturaleza, se trazó una línea divisoria que ha traído consecuencias alarmantes en materia ecológica.

De las experiencias estoicas en particular rescata un concepto que haría posible pensar la moral de la emergencia desde un horizonte más vasto. El ideal de la vida simple de los estoicos tiene su antecedente en la filosofía de los cínicos, en quienes se planteaba como una exigencia el "regreso a la naturaleza". La moral de la Stoa agrega algo nuevo: no se trata de imitar a los animales y con ello desprendernos de los refinamientos y complicaciones de la vida ciudadana. Los seres humanos en una etapa de su vida muestran un comportamiento primario común con todo ser vivo y, en tal sentido, universal: el mostrar un impulso (hormé) hacia su preservación o hacia una apropiación o pertenencia de sí mismo (oikéiosis autó) de lo cual poseen cierta sensibilidad o sentimiento.

Esa noción de apropiación o pertenencia, acentúa Roig, que es atribuida a todo animal respecto de sí mismo, se designa con el sustantivo 
oikéiosis. Se trata de las mismas relaciones naturales o de parentesco (oikéioma) que caracteriza la vida de nuestro hogar o casa (oikos u oikía); estas relaciones:

no sólo nos ponen frente a lo que sería común a todos los seres vivos sino, además, a lo que es un cierto orden, una cierta acción ordenada respecto de la preservación de la CONSTITUCIÓN de cada uno, sino también mediante la consecución de lo necesario para aquella preservación, o el rechazo de lo que la amenaza (Roig 2002 81).

Es posible hablar de "conducta" en tanto hay una teleología, aun cuando no se pueda hablar de una plena conciencia sino de una sensibilidad y de un comportamiento en un ámbito que si bien para los seres humanos es la casa, para todos los vivientes, humanos y animales, es también esa otra casa más abarcadora: la naturaleza. Cínicos y estoicos proponen un punto desde el cual puede elevarse una moral universal, gracias a su raíz en la naturaleza compartida con los seres vivos y en ese ejercicio de la oikéiosis.

Este impulso (hormé) que lleva a los seres vivos hacia su autopreservación y autoposesión dentro de los marcos de un cierto ambiente, no es ya simplemente el conatus de Spinoza en cuanto implica continuar siendo lo que se es, en medio de una necesidad que desvaloriza la contingencia. Este matiz es el que recupera Roig en la hormé estoica y epicúrea. Lo no implicado en el conatus, entendido como el perseverar en el ser, y lo no supuesto en la hormé, entendida como el sentimiento de pertenecerse a sí mismo, se despliega cuando ambas formas de impulso son llevadas a cabo "humanamente". Esto es, el ser que puede realizar el auto y hétero-reconocimiento. De este modo, la dignidad se funda en considerarse valioso al mismo tiempo que se consideran valiosos a los demás. Esa dignidad, entonces, queda definida, una vez más, desde lo que Kant denomina "reino de los fines" y desde lo que Marx llama "modos intrínsecos de ejercer el valor", más allá de los valores de uso y de los valores de cambio (cf. Roig 2002 83).

Los modos del a priori antropológico del conatus y de la hormé los comparte el ser humano con todo ser viviente. Con relación a todas 
las formas de vida, resalta Roig, no puede ejercerse ninguno de esos impulsos nombrados si se quiebra la oikéiosis o tal como lo expresaron los romanos, la conciliatio. No se puede negar a la naturaleza un valor (dignidad) que para todo ser vivo tiene su origen en ella.

Esta reflexión alcanza en el decurso del análisis de Roig dimensiones más profundas al tratar de dar respuesta a la pregunta si es posible y pertinente pensar en una moral que incluya a la naturaleza. Algunas dificultades que presentaría una moral que incluya a la naturaleza son advertidas por el filósofo mendocino. La primera es que "vivimos manipulando la naturaleza, pero no tenemos acceso directo a ella, sino por intermedio de una inevitable 'segunda naturaleza', la cultura" (Roig 2002 84). Una vez más se presenta el problema de las mediaciones, inevitables, entre las que ocupa un lugar preponderante el lenguaje. La tarea de simbolización es propia del ser humano, el signo permite dominar el mundo, a otros seres humanos también, por su posibilidad de alejamiento o no inmediatez. Ahora bien, la cultura no se resuelve únicamente en lenguaje, tiene manifestaciones infinitas. Basado en esto se produce, precisamente, el quiebre entre la vida (bios) y animalidad (zoé) sobre el que se funda todo antropomorfismo. Esta distinción entre bios y zoé la rescata Roig del pensamiento de Ignacio Ellacuría.

Otra de las dificultades es que "somos naturaleza", mas la conducta es ordenada sobre los principios de una moral reductiva, que margina la inserción del ser humano en la naturaleza. Si la moral se reduce solo al "acto libre" es imposible hablar de moral más allá de lo humano y por lo tanto una vez más quedan desarticuladas bios y zoé.

La tercera aporía enunciada por Roig gira en torno a la paradoja que se sostiene en el hecho de que integramos la naturaleza, en cuanto seres biológicos, pero nos identificamos como sujetos mediante un acto de negación de la naturaleza. En otras palabras, integramos la naturaleza pero nos diferenciamos constantemente, como sujetos, mediante las producciones culturales, y mediante formas diversas de negación de lo natural. En este caso se trata de un modo de operar de la categoría de Aufhebung hegeliana. La negación dialéctica se presenta organizada como bios contra zoé. En este marco de com- 
prensión un paisaje salido de manos de un pintor vale más que una puesta de sol en el océano. La identificación se organiza sobre una progresiva lucha contra la naturaleza, y lo humano del hombre radica en lo que no es "natural". Es así que el secreto de esta dialéctica se encuentra en una axiología "crudamente antropocéntrica" en la que el nivel primario de la moral es descalificado en función de una eticidad superadora.

La cuarta aporía mencionada por Roig es la siguiente: el ser humano, en cuanto ejerce su dominio sobre la naturaleza, se humaniza, pero en ese proceso de dominación, somete a aquellos otros seres humanos que justamente necesita para su humanización. Esta aporía está vinculada a la afirmación de Descartes según la cual el hombre es definido como amo y señor de la naturaleza en el Discurso del Método. En ese marco la universalidad del "buen sentido" o "razón" no es tal, en tanto no basta tener buen ingenio, sino que es menester aplicarlo bien. De modo tal que el mejor y más bien intencionado pedagogismo regula la manera de ejercer la razón por parte de esa humanidad que se arroga el principio mismo de una "razón bien razonada", a la vez que funda el sistema de relaciones humanas en el proceso de "dominación" y "señorío" de la naturaleza (cf. Roig 2002 86-87).

Las aporías no siempre han tenido la misma fuerza, pero hacia fines del siglo XX e inicios del siglo XXI, como consecuencia de la explotación de los recursos naturales y la progresiva destrucción de la biota, cobró fuerza la idea de que el hombre en cuanto depredador y degradador del entorno es depredador y degradador de sí mismo. En este marco Roig se pregunta si es posible pensar recursos identificatorios para el ser humano que no lo pongan al margen de la naturaleza. La vía por la que encuentra una respuesta es por el tema de la corporalidad. En las raíces cínicas, estoicas y epicúreas así como en Ignacio Ellacuría pueden rastrearse ideas valiosas para esta búsqueda. Si se pretende dar una respuesta a la segunda dificultad enunciada, afirma Roig, será necesario profundizar la noción de dignidad, mostrar que la dignidad humana y la dignidad tienen que ver con la corporeidad y con la naturaleza.

El concepto de oikéiosis, piensa Roig, permitiría alcanzar niveles alternativos de comprensión en la dirección mencionada. En este sentido, 
sería posible pensar la aceptación de un orden inmanente propio de la naturaleza, dentro de la cual no somos lo que está "fuera", ni por encima, sino plenamente dentro del mismo orden. En este caso:

No se trata de una "dignidad" entendida como fruto de aquel "reconocimiento" mutuo entre los seres humanos y que se dirige a subrayar nuestra autoconciencia como atributo identificatorio absoluto, sino una "dignidad" que se establece a partir de la responsabilidad que tenemos en cuanto seres "naturales", de la cual debemos ser capaces de tomar conciencia. Con esto, el a priori antropológico adquiere bases más amplias y mayor riqueza, lo que justifica el ejercicio de un antropomorfismo legítimo, por cuanto es nuestra propia forma la que deberíamos tratar de vivir ahora de otra manera (Roig 2002 88-89).

De este modo sería posible un despertar de la conciencia moral más amplia que la requerida por el imperativo kantiano, sin quitarle la validez que tiene esta idea reguladora. En el marco de la oikéiosis, aun cuando los entes de la naturaleza y los seres vivos (no humanos) puedan ser, y lo son, medios para la satisfacción de las necesidades humanas, estas se regulan por una categoría de dignidad más amplia.

La doctrina estoica de la oikéiosis, que enfatiza la tendencia del ser vivo a favor de su propia "constitución", ofrece la posibilidad de comprender que los animales, dentro de sus propias cadenas teleológicas, no son medios sino fines intrínsecos. Y si de hecho, dentro del desarrollo de la vida en el planeta, son los seres vivos también medios, se puede afirmar que lo son en cuanto medios para el cumplimiento de teleologías de otras cadenas vivas. Sin embargo, esto no es algo que esté predeterminado, no se trata de un orden establecido previamente por una sabiduría suprema.

Para mantener la existencia, entendida como zoé, es necesario ordenar la vida de cada día (bios). "Una vida desarreglada, la acorta: una vida ordenada, la resguarda, aun cuando todo esto no lo sea necesariamente" (Roig 2002 95). El problema de la cotidianidad (bios), que es a su vez historia, radica en la actitud ante las necesidades de la vida. 
Retomemos con palabras de Roig la definición de la oikéiosis:

El impulso (hormé) de conservación que todo ser vivo muestra y que se expresa en una sensación (synáithesis) de su propia constitución (systasis), supone una apropiación de sí mismo (okéiosis autó). Así, pues, todo animal ejerce un acto de "posesión de sí" que le es "familiar", vale decir, un acto que si bien es cumplido por parte de cada uno, lo es dentro de un ámbito común para todos, la naturaleza en cuanto oikos u oikía, acto al que se denomina oikéiosis (2002 96).

De modo tal que en el marco del estoicismo no hay "esclavos por naturaleza", ni puede afirmarse que la mujer dependa de leyes que le son específicas: las de los dioses subterráneos, frente a los varones que dependerían de las leyes de los dioses celestes. El marco de sentido de la oikéiosis permite afirmar la igualdad sobre una base que es común con todo ser vivo. Séneca denominó a la oikéiosis como "conciliatio", que en él significa "afirmarse a sí mismo" y "apropiarse de sí mismo". La conciliatio mienta el "conciliarse" con su propia naturaleza (constitutio) y con la Naturaleza (natura).

En suma, la universalidad del principio de la oikéiosis o conciliatio posibilita justificar desde el nivel de la animalidad (zooeidad) las ansias de una vida (bios) autónoma, libre, en el sentido de desatamiento, una vida liberada de cadenas impuestas. Ambas categorías, oikéiosis y conciliatio, fueron fundantes para establecer los principios de la moral tanto para cínicos, estoicos y epicúreos (cf. Roig 2002 97-98).

El itinerario del análisis de Roig se completa con la propuesta filosófica de Ignacio Ellacuría. Uno de los ejes del pensamiento del filósofo español-salvadoreño, comprometido con la praxis de liberación en América Latina, es el de la necesaria conciliación o reencuentro con el mundo, la oikía que compartimos con los demás seres vivos. Su filosofía, en filiación con la de Xavier Zubiri, su maestro, acentúa la necesidad de rescatar el bios de la zoé, la vida en la existencia. No se trata de un existencialismo, según Roig, sino de un materialismo que intenta alcanzar desde la base vital del ser humano, una integración 
con lo desintegrado por otra vía que la de idealismos e intelectualismos. En La filosofía de la realidad histórica (Ellacuría 1991) define la "temporalidad de la realidad humana" sobre la base de las categorías de bios y zoe, lo cual muestra que en el pensar contemporáneo la amenaza de la destrucción ha impulsado una inquietud por volver a pensar la naturaleza del hombre y la naturaleza. Arturo Roig propone como alternativa viable la elaboración de una filosofía de la corporeidad para la cual cínicos, estoicos, epicúreos y Ellacuría han dado elementos conceptuales valiosos.

El "tiempo del hombre" no se entiende, para Ellacuría, si no se parte de la "vida", y no se entiende la "vida" si no se alcanza una comprensión de sus dos manifestaciones: bíos y zoé. Para Ignacio Ellacuría el hombre ni es pura naturaleza, ni es puramente historia: es a la par naturaleza e historia. Aunque los idealismos antropológicos reduzcan al hombre a su no animalidad y los naturalismos lo reduzcan a uno entre otros fenómenos de la naturaleza, es necesario sobrepasar esas reducciones o esos dualismos. Esto se logra "haciendo que el bíos humano sea zoográfico y que la zoé humana sea biográfica".

Hay en el pensamiento de Ellacuría un rescate de la "materialidad humana" desde el cual se recupera la historia, la realidad histórica. Se comienza por el sentir, sentir el mundo. Este será para el filósofo salvadoreño el punto de partida para un filosofar en clave de liberación. Al enfrentarse con las cosas como realidad el viviente se comporta, dice, integral y unitariamente. Lo que el hombre tiene primariamente en el ejercicio inicial de su inteligencia es la realidad imprevisiblemente sentida: es la sensibilidad animal la que lo "fuerza" a inteligir y la que hace que ese inteligir sea inexorablemente un inteligir sentiente. Sin ese momento "animal" ni la inteligencia, ni la voluntad, ni el sentimiento, podrían haber aparecido ni ejercido. De este modo la zoé es el fundamento del bíos, así como el bíos liberado de la zoé será la salvación de la zoé. El viviente humano no puede seguir viviendo biológicamente más que haciéndose cargo realmente de su situación.

La liberación toma en este caso el carácter preciso de un proceso hacia la libertad a partir de la naturaleza, afirma Roig. El dinamismo de la 
realidad lleva a nuevas formas de realidad, se trata de un proceso de liberación. Arturo Roig recupera la filosofía de Ellacuría pues entiende que su planteo supera la noción de "libertad interior" propia de espiritualismos e intelectualismos que reducen el problema moral a un acto de conciencia. La liberación se entiende, consecuentemente, como un proceso que se plasma en un crecimiento de la realidad, en un incremento de sustantividad, individualidad y mismidad. Es así que esta perspectiva se inscribe en la tradición de la moral de la emergencia y se muestra como una versión nueva, en el sentido de distinta, del "regreso a la naturaleza".

\section{A modo de conclusión}

La comprensión de la realidad moral como un ámbito transido de líneas conflictivas no implica una defensa de relativismos morales. Roig resemantiza en su reflexión moral una categoría como la de dignidad humana, la que se constituye en idea reguladora de la moral emergente. La dignidad humana no es otra cosa que el ejercicio del $a$ priori antropológico, y este implica una "posición de sujeto". Así como no hay una sola forma de ejercer aquel a priori, no hay una sola forma de ser sujeto digno. Cada posición de sujeto implica la posibilidad de una emergencia y por ello mismo una esperanza.

Pueden visualizarse elementos precisos que muestran la preocupación profunda de Arturo Roig por reflexionar y orientar la tarea moral de nuestro tiempo. En primer lugar, se destaca la resemantización de ciertas categorías, entre ellas la de dignidad humana, ampliada a partir del concepto de oikéiosis. Complementariamente, es relevante la propuesta de retomar una tradición moral propia de nuestra América. Un tercer elemento que se destaca es el reconocimiento que se le otorga al saber práctico moral, hecho evidente que acerca al autor mendocino a la concepción kantiana de la moral y lo aleja de la posición hegeliana como devaluadora de este saber. La reflexión moral de Roig constituye una clara contribución a la construcción de una sociedad civil en el sentido de una sociedad libre, igualitaria y justa. Sociedad que solo será posible en la medida que 
se constituya como morada, como ethos, de seres humanos dignos intrínsecamente que se consideren a sí mismos y a los otros como fines y nunca como medios.

Los alcances de la dignidad entendida como fundamento se amplían cuando se la entiende desde el marco de la oikéiosis. Esta connotación ofrece la posibilidad de no limitar el ejercicio de las normas morales a una posición antropocéntrica, pues el erigir al hombre como centro no implica un ejercicio legítimo en todos los casos. Se trata de una reelaboración categorial que constituye un aporte significativo en la reflexión moral latinoamericana.

\section{Bibliografía}

Ardao, Arturo. Espacio e inteligencia. 1983. Caracas: Fundación de Cultura Universitaria / Montevideo: Biblioteca de Marcha, 1993.

Arpini, Adriana (comp.) América Latina y la moral de nuestro tiempo. Estudios sobre el desarrollo de la razón práctica. Mendoza: EDIUNC, 1997.

Cerutti Guldberg, Horacio. Filosofando y con el mazo dando. Madrid: Biblioteca Nueva /Universidad Autónoma de la Ciudad de México, 2009.

De Zan, Julio. "La interpretación hegeliana de la dinámica de la sociedad civil en Europa y en América", Cuadernos Salamantinos de Filosofía 8 (1981): 39-62.

De Zan, Julio. "Decir que no", Tópicos 10 (2002): 137-150.

De Zan, Julio. "La Filosofía de la Liberación de los años '70 y la Argentina de comienzos del S. XXI", Erasmus. Revista para el diálogo intercultural V 1/2 (2003): 29-46.

De Zan, Julio. La ética, los derechos y la justicia. Montevideo: Konrad Adenauer - Stiftung E.V., 2004.

De Zan, Julio. "Universalismo y particularismo en la ética de Kant", Tópicos [online] 13 (2005): 63-89. Disponible en: http://www.scielo.org.ar/ pdf/topicos/n13/n13a04.pdf [Consultado el 01.10.2015]

De Zan, Julio. La gramática profunda del ethos: una lectura de la ética de Kant. Buenos Aires: Las Cuarenta, 2013.

Ellacuría, Ignacio. Filosofía de la Realidad Histórica. Madrid: Trotta, 1991.

Ellacuría, Ignacio. "Filosofía, ¿para qué?", Escritos filosóficos 3 (2001): 115-131. 
Espeche, Ernesto. "Derechos humanos". Diccionario del pensamiento alternativo. Hugo Biagini y Arturo A. Roig (directores). Buenos Aires: Biblos, 2008. 155-157.

Fernández Nadal, Estela. "Arturo Andrés Roig". Semillas en el tiempo. Clara Jalif de Bertranou (comp). Mendoza: EDIUNC, 2001. 165-187.

Kant, Immanuel. La metafísica de las costumbres. Madrid: Tecnos, 1989.

Kant, Immanuel. Fundamentación de la metafísica de las costumbres. México: Porrúa, 1996.

Kant, Immanuel. Fundamentación de la Metafísica de las costumbres. Buenos Aires: Las Cuarenta, 2012.

Kant, Immanuel. Crítica de la Razón Práctica. México: Porrúa, 2013.

Maliandi, Ricardo. "Conflictividad". Diccionario del pensamiento alternativo. Hugo Biagini y Arturo A. Roig (directores). Buenos Aires: Biblos, 2008. 115-117.

Maliandi, Ricardo. Ética: conceptos y problemas. Buenos Aires: Biblos, 2009.

Maliandi, Ricardo. Ética convergente. Fenomenología de la conflictividad. Tomo I. Buenos Aires: Las Cuarenta, 2010.

Michelini, Dorando. "Dignidad humana en Kant y Habermas", Estudios de Filosofía Práctica e Historia de las Ideas 12 (2010): 91-99.

Muñoz, Marisa y Patrice Vermeren (comp.). Repensando el siglo XIX desde América Latina y Francia. Homenaje al Filósofo Arturo A. Roig. Buenos Aires: Colihue, 2009.

Muñoz, Marisa. "Arturo Andrés Roig". El pensamiento filosófico latinoamericano, del Caribe y "latino" (1300-2000). Historia, corrientes, temas y filósofos. Enrique Dussel, Eduardo Mendieta y Carmen Bohórquez (eds.). México: CREFAL / Siglo XXI Editores, 2009. 880-883.

Oviedo, Gerardo. "Arturo Andrés Roig, lector de Spinoza", Estudios de Filosofía Práctica e Historia de las Ideas 12 (2010): 101-115.

Oviedo, Gerardo. "Arturo Roig, una escritura filosófica emergente", Horizontes Filosóficos. Revista de Filosofía, Humanidades y Ciencias Sociales 3 (2013): 121-144.

Petit, María Angélica. "Latinoamérica ante la globalización y la conflictividad. Reportaje a Arturo Andrés Roig". Cuadernos de Marcha 173 (2001).

Ramaglia, Dante. "Filosofía latinoamericana: humanismo y emergencia en la obra de Arturo Andrés Roig". Cuyo. Anuario de Filosofía Argentina y Americana 31/ 1 (2014): 53-67. 
Roig, Arturo. "Condición humana, derechos humanos y utopía", Contracorriente 4 (2001).

Roig, Arturo. Ética del poder y moralidad de la protesta. Mendoza: EDIUNC, 2002.

Roig, Arturo. El pensamiento latinoamericano y su aventura. Buenos Aires: Ediciones El Andariego, 2008.

Roig, Arturo. Teoría y crítica del pensamiento latinoamericano. Buenos Aires: Una Ventana, 2009.

Roig, Arturo. "Juan Montalvo: eticidad, conflictividad y categorías sociales". Diversidad e integración en Nuestra América. Volumen I: Independencia, Estados nacionales e integración continental (1804-1880). Adriana Arpini y Clara A. Jalif de Bertranou (2010) (Directoras). Buenos Aires: Biblos, 2010. 281-299.

Roig, Arturo. Rostro y filosofía de nuestra América. Buenos Aires: Una Ventana, 2011 a.

Roig, Arturo. "La integración alma-cuerpo en Epicuro", Estudios de Filosofía Práctica e Historia de las Ideas13 (2011b): 11-15.

Senent, Juan Antonio (ed.). La lucha por la justicia. Selección de textos de Ignacio Ellacuría (1969-1989). Bilbao: Universidad de Deusto, 2012.

Spinoza, Baruj. Ética demostrada según el orden geométrico. Madrid: Trotta, 2000. 